\title{
Deformation analysis of an unsaturated geosynthetic reinforced soil wall subjected to infiltration
}

\author{
Fernando H. M. Portelinha ${ }^{1, *}$, Jorge G. Zornberg ${ }^{3}$, and Orencio M. Vilar ${ }^{3}$ \\ ${ }^{1}$ Federal University of Sao Carlos, Civil Engineering Department 13565905 Sao Carlos, Brazil \\ ${ }^{2}$ The University of Texas at Austin, Civil Engineering Department, 78712, Austin, USA \\ ${ }^{3}$ University of Sao Paulo, Engineering School of Sao Carlos, 13566590, Sao Carlos, Brazil
}

\begin{abstract}
Geosynthetic-reinforced soil walls are structures typically constructed with compacted and thus unsaturated soils. The use of local fine-grained soils as backfill material has been a common practice in view of the significant cost reduction in comparison to granular backfills. This is especially applicable in tropical areas where lateritic soils are found as these material scan exhibit outstanding geotechnical properties mainly under unsaturated conditions. Thus, it is possible to optimize the design and construction of geosyntheticreinforced soil walls considering soil unsaturation, however it is not known to what extent infiltration can reduce soil suction impairing the safety of the structure. To address the influence of suction on the behavior of geosynthetic structures, a full-scale geotextile-reinforced wall was subjected to infiltration and instrumented to capture the distribution of moisture and soil suction along the reinforced zone, as well as reinforcements strains. This paper presents and discuss the influence of geotextile reinforcement acting as capillary barrier coupled with the wall performance. Results demonstrate that the advancement of infiltration front has a more pronounced effect on deformation as the changes on water contents. Capillary barriers were found to occur retarding infiltration, but not affecting the overall performance of the structure. The average of monitored suction values along the wall height, herein called as "global suction", was found to be strictly related to maximum reinforcement strains behavior.
\end{abstract}

\section{Introduction}

Many standards recommend the use of granular soils as backfill of mechanically stabilized earth; however, the use of local fine-grained soils can significantly reduce costs when granular materials are difficult to access. In tropical areas, geotechnical engineers account with the advantage of using lateritic fine-grained soils. It is also known that the unsaturated condition can improve their properties, reducing the permeability and compressibility, and increasing the shear strength. Thus, it is possible to optimize the design and construction of geosyntheticreinforced soil walls considering soil unsaturation, however it is unknown to what extent infiltration can reduce soil suction impairing the safety of the structure.

In general, the unsaturated condition of the backfill soil can persist for a long time, depending on the local precipitation regime and evaporation rates of the region. When geotechnical structures are built in unsaturated soil conditions, design analyses based on unsaturated soil mechanics provide accurate predictions of performances.

Although many studies have reported serviceability problems of reinforced soil structures using local finegrained soils, especially considering their susceptibility to pore water pressure development (Zornberg and Mitchell 1994 [1]; Koerner and Soong 2001 [2]; Yoo and Jung
2006 [3]; Portelinha and Zornberg 2017 [4]), a number of studies have controversially reported adequate performance of these structures, even when subjected to significant periods of rainfall events (Carvalho et al. 1986 [5]; Mitchell and Zornberg 1995 [6]; Portelinha et al. 2013 [7], 2014 [8]).

Since the water pressures within an unsaturated soil mass are negative, their understanding requires evaluation of the unsaturated hydraulic characteristics of geosynthetic reinforcement, backfill, and interfaces. Zornberg et al. (2010) [1] reports the development of capillary barriers when nonwoven geotextiles underlay unsaturated fine-grained soils. This is because under unsaturated conditions the hydraulic conductivity of nonwoven geotextiles is typically lower than that of the soil. This phenomenon results in additional storage of moisture at the soil-geosynthetic interface until the suction decreases below a value identified as the "breakthrough" suction. The capillary break effect has been observed to increase the water storage capacity of soils (Khire et al. 2000 [10]).

Other relevant aspect to be assessed in unsaturated reinforced soil structures is the fact that suction might change when subject to infiltration resulting in reduction on shear strength and shear modulus of soil. In the last decades, many studies have been dedicated to describing

\footnotetext{
* Corresponding author: fportelinha@ufscar.br
} 
the effect of suction on the shear strength of soils (Fredlund and Morgersten 1977 [11], Fredlund et al. 1978 [12], Vanapalli et al. 1996 [13], Khalali and Khabazz 1998 [14]). Studies have also been conducted to describe the relationship between suction and shear modulus of soil (Marinho et al. 1995 [15], Mancuso et al. 2002 [16], Ng and Yung 2008 [17], Ng and Xu 2012 [18], Georgetti et al. 2013 [19]). Generally, authors have reported that the shear modulus increases until a certain value of suction from which no significant increases in modulus is reached. The rate of increasing declines when the suction is higher than the air-entry value of the soil.

Considering the limited information currently available on the effect of water infiltration on the overall performance of geotextile reinforced walls, this study includes quantification of wall deformations that are induced during infiltration. Accordingly, an important objective of this paper is to evaluate the infiltration processes into the unsaturated fill in a geotextilereinforced wall and their effect on the structure mechanical response. This is achieved by monitoring the performance of a large-scale reinforced soil wall. The experimental program focuses specifically on the impact of infiltration in a wall reinforced with nonwoven geotextiles and uses reinforcement strains as key aspects to quantify the wall performance.

\section{Experimental program}

The experimental program in this study involved monitoring the hydraulic and deformation responses of a full-scale geotextile-reinforced wall subjected to infiltration. The characteristics of the wall reported in this paper are discussed below.

\subsection{Materials}

A Full-scale model was constructed using a lateritic soil. Physical properties of the soil are reported in Table 1 . The soil includes approximately $40 \%$ of fine particles. As this study focus in an unsaturated behavior of soil-geotextile interface, the soil water retention curve is provided in Figure 1.

Table 1. Characteristics of the backfill soil

\begin{tabular}{lll}
\hline Properties & Standard & Values \\
\hline Sand fraction & & $56 \%$ \\
Silt fraction & ASTM D422-63 & $12 \%$ \\
Clay fractiont & & $32 \%$ \\
$\mathrm{G}_{\mathrm{s}}$ & NBR6508 & 2.75 \\
Liquid Limit & NBR6459 & $40 \%$ \\
Plasticity index & NBR 7180 & 19 \\
Maximum dry unit weight & ASTM D1557 & $17.88 \mathrm{kN} / \mathrm{m}^{3}$ \\
Optimum water content & ASTM D1557 & $14.6 \%$ \\
Cohesion & ASTM D7181 & $15 \mathrm{kPa}$ \\
Friction angle & ASTM D7181 & $32^{\circ}$ \\
Hydraulic conductivity & NBR14545 & $4.9 \times 10^{-7} \mathrm{~m} / \mathrm{s}$ \\
\hline
\end{tabular}

The reinforcement is a polyester needle-punched nonwoven geotextile. Physical, mechanical, and hydraulic properties of the nonwoven geotextile, which are of relevance in this study, are summarized in Table 2. The geotextile water retention curve was obtained by desorption techniques following the procedures reported in ASTM D6836. Fig. 2 shows the geotextile water retention curve along with that of the backfill soil. The water retention curve of the nonwoven geotextile shows a highly nonlinear response, with a significant decrease in volumetric water content (or degree of saturation) within a comparatively narrow range of suction. The air entry value and overall shape of this geosynthetic material is consistent with that reported in other studies (e.g. Zornberg et al. 2010 [9]).

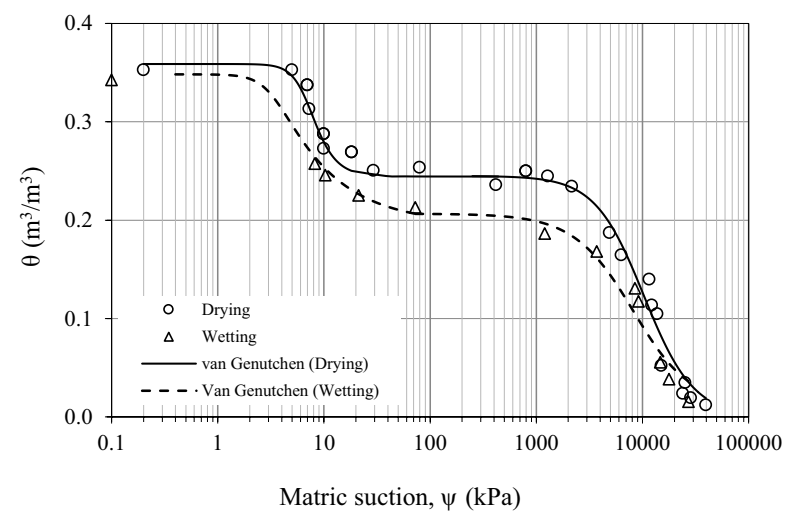

Figure 1. Water retention curve of the backfill soil.

Table 2. Properties of the nonwoven geotextile

\begin{tabular}{lll}
\hline Properties & Standard & Values \\
\hline Weight per unit area & ASTM D5261 & $293 \mathrm{~g} / \mathrm{m}^{2}$ \\
Thickness & ASTM D5199 & $2.96 \mathrm{~mm}$ \\
Permittivity & ASTM D4491 & $1.96 \mathrm{~s}^{-1}$ \\
Transmissivity & ASTM D4716 & $6 \times 10^{-6} \mathrm{~m}^{2} / \mathrm{s}$ \\
Apparent opening size & AFNOR G38-017 & $93 \mu \mathrm{m}$ \\
Tensile strength & & $12 \mathrm{kN} / \mathrm{m}$ \\
Elongation at failure & & $83 \%$ \\
\hline
\end{tabular}

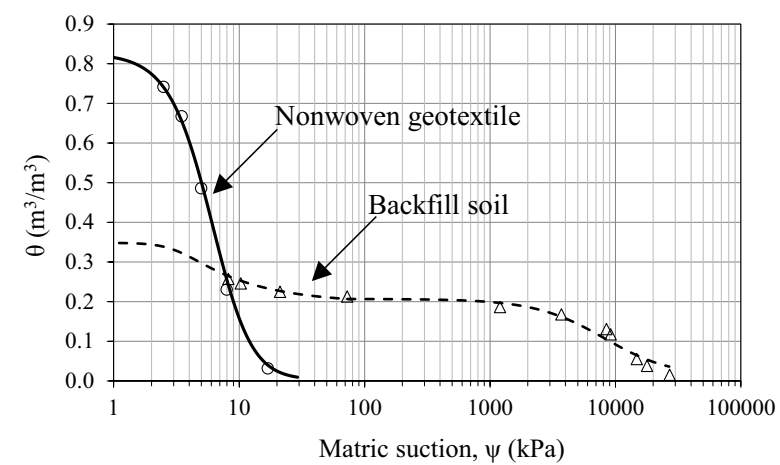

Fig. 2 - Water retention curve of the backfill soil and the geotextile.

According to Zornberg et al. (2010) [9], the breakthrough suction corresponds to the value for which both the backfill soil and the geotextile have the same unsaturated hydraulic conductivity value. Fig. 3 illustrates the hydraulic conductivity functions (k-functions) of the geotextile and the backfill soil used in the full-scale walls. These curves were obtained using the data from water retention curves for both materials (Fig. 2) to develop fitting parameters for the van Genuchten model (van Genuchten 1980 [20], Mualem 1976 [21]). 


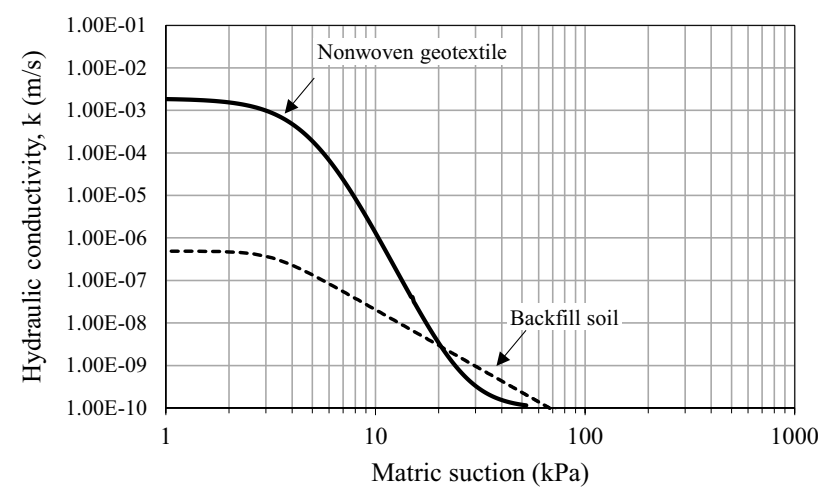

Fig. 3. K-functions of backfill soil and nonwoven geotextile.

\subsection{Full scale model}

A Full-scale wall was constructed inside a steel frame with $1.8 \mathrm{~m}$ height by $1.55 \mathrm{~m}$ width, with backfill soil extending to $1.8 \mathrm{~m}$ from the front edge of the metallic box. The soil was compacted to $98 \%$ of relative density and optimum water content in relation to standard Proctor (Table 1). To obtain the required relative density, compaction was performed manually in $5 \mathrm{~cm}$ high layers. Compaction control was achieved using the drivecylinder method (ASTM D2937), spiked every compacted layer reaching $30 \mathrm{~cm}$ height. The backfill soil was placed over a rigid concrete foundation.

Geotextile reinforcements were placed at $30 \mathrm{~cm}$ vertical spacing with a declivity of $1 \%$ towards the face. Each layer of reinforcement had a total length of $1.60 \mathrm{~m}$ measured from the face. The wall was constructed with no facing batter and using the wrap-around technique. Protective shotcrete coating ranging in thickness from 5 to $8 \mathrm{~cm}$ was used. Drainage geocomposites were used as face drainage elements into the second and forth reinforced layers, extending to $30 \mathrm{~cm}$ from the face forward into the wall. Figure 4 a presents the cross-section view of the model, while Figure $4 \mathrm{~b}$ shows a photograph during test.

After construction of the wall, a wetting system was installed on the top of the wall surface. The wetting system includes supplying pipes and a water distribution layer placed over the structure. The water distribution layer involves a $15 \mathrm{~cm}$ high sand layer and a drainage geocomposite installed over the sand layer. The configuration of the drainage geocomposite and the sand layer provided a uniform water distribution over the top surface. Water was supplied by a reservoir with a float switch enabling constant hydraulic head to induce a uniform rainfall intensity. The intensities of precipitation were controlled by defining of volumetric flow rate in the output water tap installed in the water reservoir.

\subsection{Instrumentation and test procedure}

Instrumentation was installed to monitor matric suction of the soil pore water pressures, water content, internal horizontal displacements, and horizontal face displacements. The instruments layout is presented in Fig. 6. Geotextile strains were calculated using the relative displacements between consecutive mechanical extensometers (tell-tales) and dividing them by the initial distance between points of measurement.

The advancement of water infiltration into the model was monitored using tensiometers with a measurement range of -100 to $100 \mathrm{kPa}$ placed in each reinforced layer $5 \mathrm{~cm}$ over the reinforcements. Frequency domain reflection sensors (FDR) were installed to measure the water content in each reinforced layer (located $15 \mathrm{~cm}$ over the reinforcement). Four columns and five lines of sensors were specifically concentrated on layer 5 (upper layer) to evaluate capillary barriers effects (Fig 6b).

Data from the multiple instruments installed in the full-scale model were collected during wetting simultaneously. An infiltration rate of $1.8 \times 10^{-7} \mathrm{~m} / \mathrm{s}$ was applied over the full-scale model, while sustaining a uniform loading of $100 \mathrm{kPa}$ during the test. Loading was applied using air bags on the top of wall and a reaction structure. No pounding occurred on the top of the wall, because the water flow imposed was lower than the hydraulic conductivity of soil (approximately 2.5 times smaller than the saturated hydraulic conductivity of the soil).

\section{Results}

Fig. 5 shows the data obtained from the moisture sensors and tensiometers over time located at the elevations of the different reinforced layers (See Fig.4a). Soil saturation was only observed in the sensor located at $25 \mathrm{~cm}$ from the top of the wall. As will be subsequently discussed, this sensor was able to capture the development of capillary break in this location. In the other layers (RL1 to RL4), where the moisture sensors were located at mid height of the reinforced layer, the increased water storage of capillary barriers could not be detected at the sensor location. Fig. 5 also illustrates transient nature of the infiltration processes.

Fig. 5b shows that the initial suction was reasonably uniform, ranging from 45 to $60 \mathrm{kPa}$. The suction readings show a drastic reduction as the infiltration front reached the location of the sensors. Minimum suction values for each sensor reached approximately $0 \mathrm{kPa}$. The exception was the reading of the tensiometer installed at $15 \mathrm{~cm}$ below the soil surface, which indicated pore water pressure values of up to $1.5 \mathrm{kPa}$. However, tensiometer readings provided evidence that positive pore water pressures did not develop along the geotextile layers. It should be noted in Fig. 5b, the infiltration front reached the moisture sensors before reaching the tensiometers in each of the soil layers as consequence of longer time required by tensiometers to stabilize than the moisture sensors. In addition, the moisture sensors are located above the tensiometers which might be a reason for this observation. 


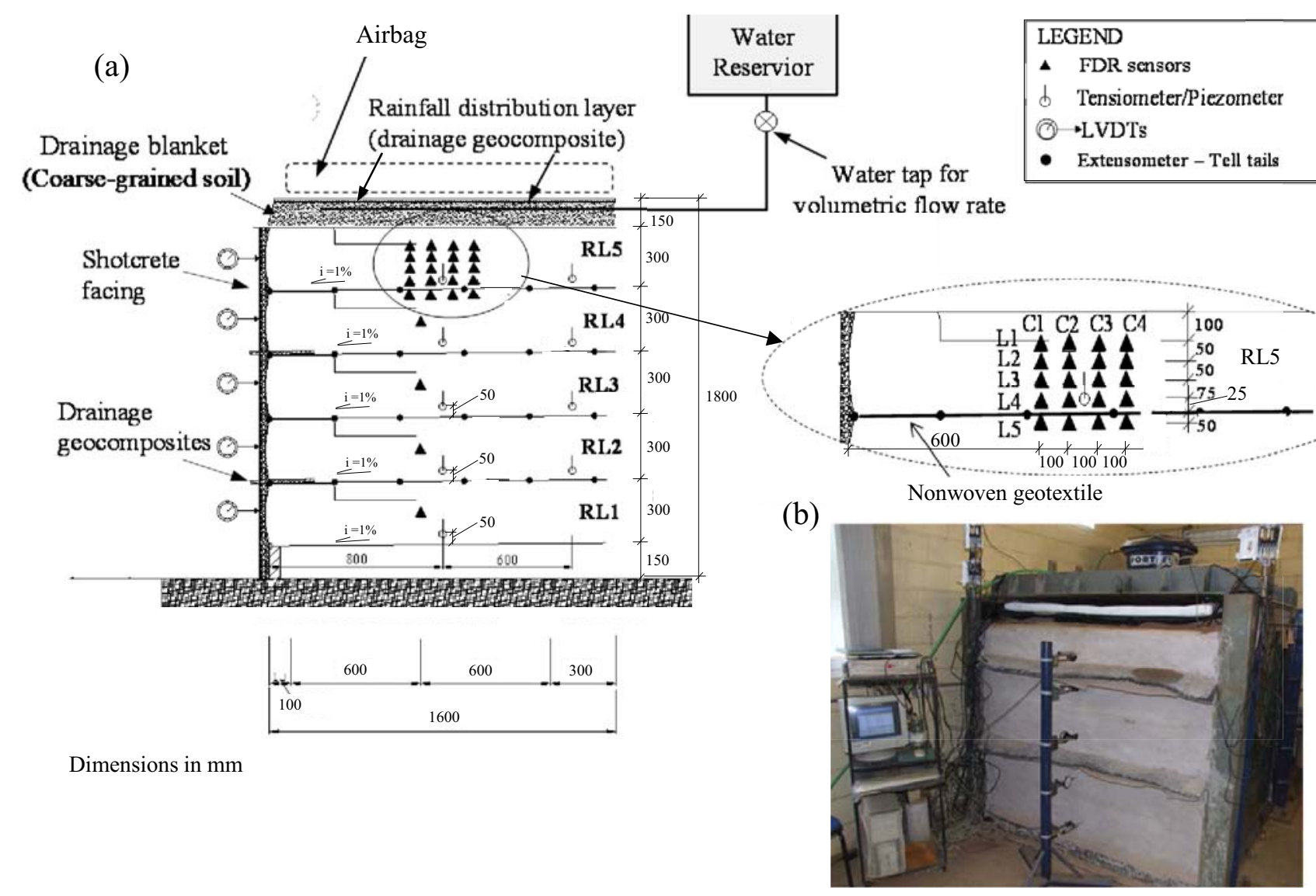

Figure 4. Full-scale model: (a) Cross section of the full-scale reinforced wall model, instrumentation layout and wetting system; (b) photograph during test.
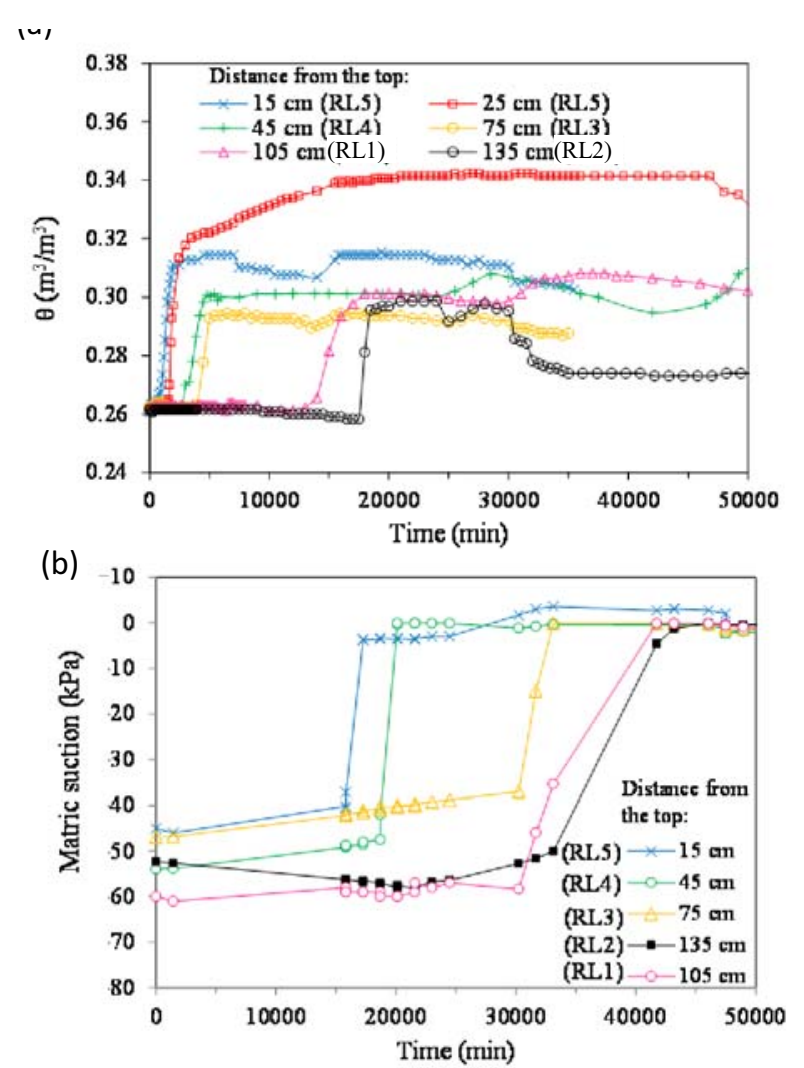

Fig 5. Responses collected during infiltration for each reinforced layer (RL): (a) Moisture content and (b) Water pressure.
Fig. 6 provides the moisture content results obtained in the vertical arrays located at the distance of $800 \mathrm{~mm}$ from the face, along reinforcement layer 5 (RL5). Three distinct phases of water flow can be identified after applying a constant infiltration rate of $1.8 \times 10^{-7} \mathrm{~m} / \mathrm{s}$. Initially, the entire profile was relatively dry, with an ascompacted volumetric water content of $0.262 \mathrm{~m}^{3} / \mathrm{m}^{3}$ that corresponds to the initial volumetric water content $\left(\theta_{\mathrm{i}}\right)$. The advancing wetting front involves a transient infiltration process under a constant impinging flow rate. As the wetting front reaches the location of each sensor, the volumetric water content is observed to increase from $\theta^{i}$ to a value of approximately $0.310 \mathrm{~m}^{3} / \mathrm{m}^{3}$ that corresponds to the equilibrium water content for this condition $\left(\theta_{\text {eq. }}\right)$. After the wetting front reached the top of geotextile (around 3,000 min. after testing initiation), the water did not immediately flow into the geotextile. Instead, a capillary break developed, and water accumulated within the soil immediately above the geotextile reinforcement. Such accumulation continued until the suction decreased to a comparatively low value, when breakthrough occurred (approximately 10,000 min. after test initiation). Due to the water storage due to development of a capillary break, the volumetric water content reached a value of approximately $0.34 \mathrm{~m}^{3} / \mathrm{m}^{3}$, which corresponds to soil saturation $\left(\theta_{\text {sat }}\right)$. 


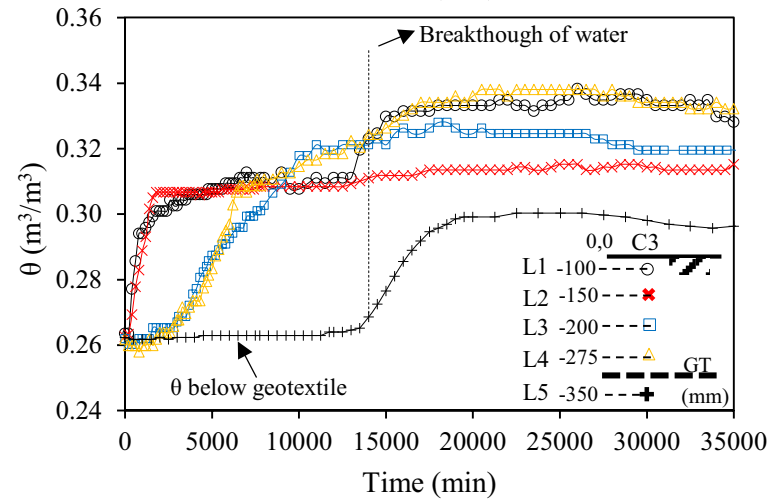

Fig 6. Moisture content measured in the upper reinforced soil layer (RL5) at $800 \mathrm{~mm}$ from the wall face (Column C3).

As a result of the development of the capillary break in RL5, infiltration into RL4 (the second layer from top layer) was delayed. Specifically, the development of capillary break led to a retardation of the infiltration by 4 days $(6,000 \mathrm{~min}$.) per reinforcement layer, until the suction decreased to allow breakthrough. At this point, the geotextiles became more permeable than the soil and downward flow occurred. According to the moisture data presented in Fig. 8, the breakthrough suction corresponds to a moisture content value of $0.33 \mathrm{~m}^{3} / \mathrm{m}^{3}$. In this study, the breakthrough suction was found to range from 6 to 10 $\mathrm{kPa}$, which corresponds to suction value obtained from the SWRC (Fig. 1) using the referred breakthrough moisture content. After breakthrough, water advanced into the underlying layer and the moisture content in the RL5 was observed to reduce to that corresponding to the equilibrium water content in flow $\left(\theta_{\text {eq. }}\right)$. The breakthrough suction could not be measured directly, as the tensiometers were not positioned immediately above the geotextile.

The breakthrough suction corresponds to the value for which both the backfill soil and the geotextile have the same unsaturated hydraulic conductivity value. Fig. 3 illustrates the hydraulic conductivity functions (kfunctions) of the geotextile and the backfill soil used in the full-scale walls. These curves were obtained using the data from water retention curves for both materials (Fig. 2) to develop fitting parameters for the van Genuchten model (van Genuchten 1980 [20], Mualem 1976 [21]). As indicated in Fig. 3, the breakthrough suction defined by the intersection of the hydraulic conductivity functions is approximately $20 \mathrm{kPa}$. Comparison of the breakthrough suction values obtained from the monitored moisture content data (Fig. 6) and from the k-functions of both materials (Fig. 3) result in comparatively similar values.

A comparison between the total volumes of water imposed and measured during infiltration is presented in Fig. 7. The imposed volume of water was defined considering the actual flow rate applied as irrigation during the test. That is, it was assumed that the entire volume of water imposed as irrigation infiltrated into the backfill soil. The volume of water infiltrated during the test was also predicted considering the changes in water storage within the backfill soil, as measured by moisture sensors. The infiltrated water volume was expected to account for the lateral flow due to the in-plane drainage capability of the geotextile reinforcements. The results show that there is practically no change in the measured infiltration during the period ranging from 1,500 to 11,000 minutes. This observation is attributed to a restricted infiltration due to the development of a capillary break." The difference between imposed and infiltrated flow rates observed in Fig. 7 may correspond to the amount of water drained through the geotextile during test (approximately $0.25 \mathrm{~m}^{3}$ ). Additionally, the results indicate that water drained within primarily through the top geotextile layer, as evidenced in Fig. 7 by the similar imposed and measured flow rate values after 10,000 minutes of test.

Fig. 8 shows the magnitude of the reinforcement peak strains $\left(\varepsilon_{\text {peak }}\right)$ and of the volumetric water content $(\theta)$ monitored throughout the test. In the case of the RL5 (upper layer), which included a denser array of moisture sensors, the sensor located at $12.5 \mathrm{~cm}$ from the geotextile (Fig. 4a) was adopted for this evaluation. For the remaining layers, only one sensor per layer was installed, which was used in this evaluation.

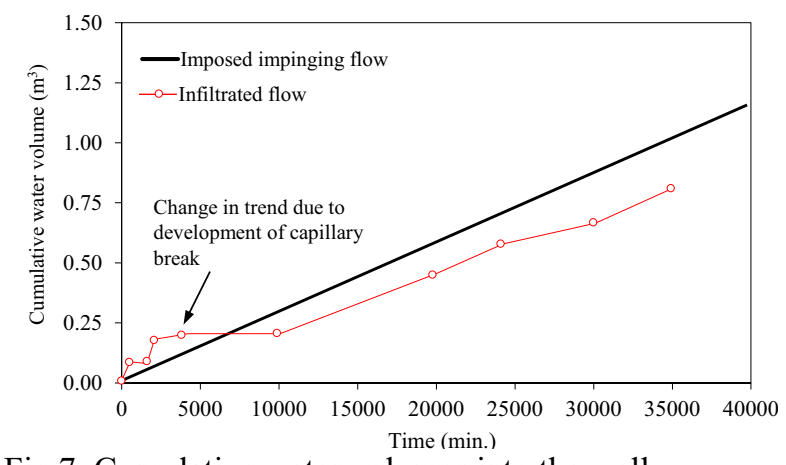

Fig 7. Cumulative water volumes into the wall.
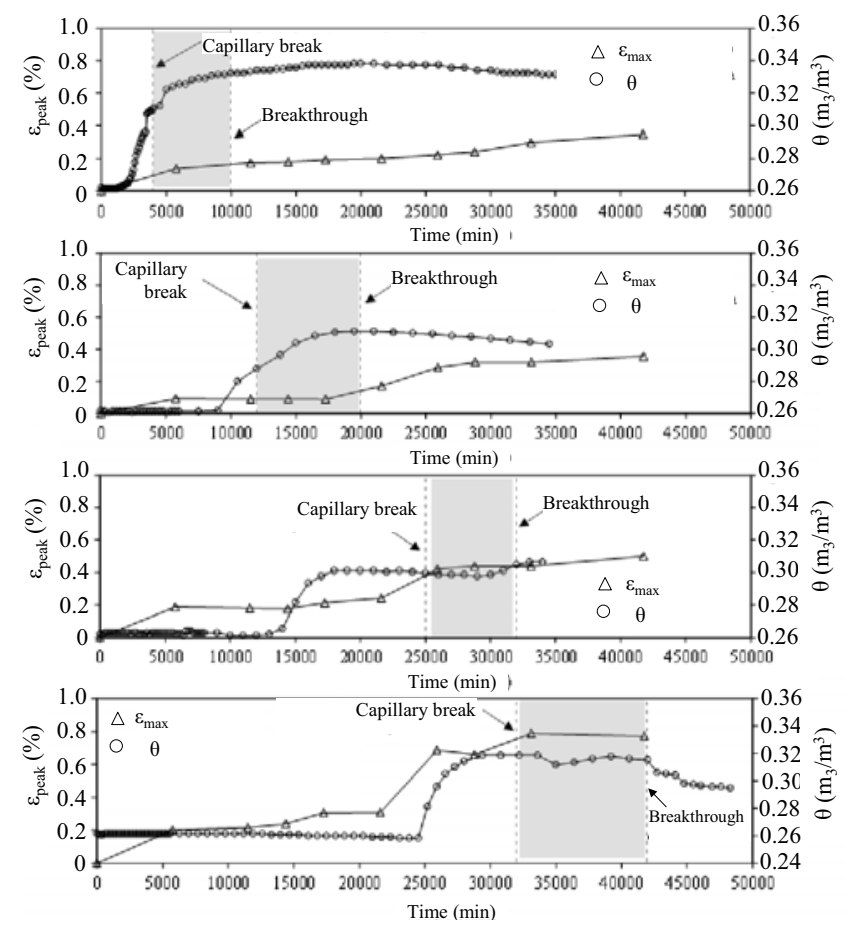

Fig 8. Geotextile peak strains $\left(\varepsilon_{\text {peak }}\right)$ during the infiltration on reinforcement layers: (a) RL5, (b) RL4, (c) RL3 and (d) RL2. 
In Fig. 8, the times corresponding to the initial development of the capillary break and to the subsequent breakthrough are also indicate in Fig. 8 to evaluate the possible impact of water storage on the wall performance. In general, the strain results show that increases in soil moisture content tend to lead to increases in the maximum reinforcement strain $\left(\varepsilon_{\text {peak }}\right)$. However, the increases in $\varepsilon_{\text {peak }}$ seems to be more strongly related to the advancement of the infiltration front into the unsaturated soil mass. For example, the results in Fig. 8a indicate that times with significant moisture changes do not necessarily correspond to the times with significant increases in reinforcement strains for the RL5. Instead, the significant increases in reinforcement strains are more evident when the infiltration front has advanced into the underlying reinforcement layer. The moisture increase (capillary break) and subsequent breakthrough of the lower layers are also observed to lead to increases in reinforcement strains. However, the moisture accumulation in top layers is observed to result in increases in geotextile strains in the multiple lower layers. Accordingly, the time history of the lower reinforcement layers shows multiple periods of strain increases.

This is an evidence that moisture advancement and consequent progressive loss of suction, can result in additional lateral movements in layers below due to the global reduction of soil mass stiffness. This phenomenon is better illustrated in Fig. 9, which allows assessment of the effect of the infiltration front on maximum peak reinforcement strains $\left(\varepsilon_{\max }\right)$ of all reinforced layers are presented. Results show that the depth of the wetting front correlates well with the maximum peak reinforcement strains (Fig. 9). That is, increases in reinforcement strains of the geotextile reinforced soil wall were found to be more strongly related to the depth of moisture front than to increases in soil moisture values.

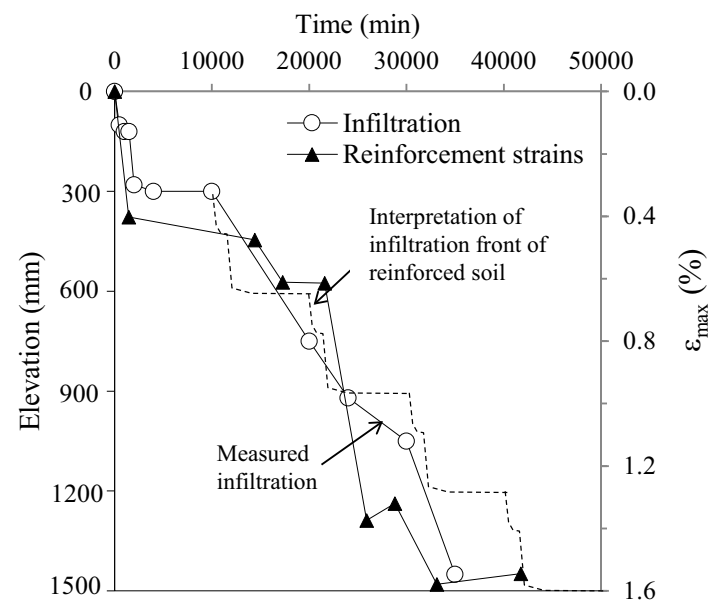

Fig 9. Effect of advancement of infiltration front on Maximum geotextile peak strains.

In Fig. 10, measured maximum reinforcement peak strains $\left(\varepsilon_{\text {peak }}\right)$ are plotted as function of cumulative volume of water imposed during the test. Similarly, maximum peak reinforcement strains $\left(\varepsilon_{\max }\right)$ (Fig. 11) are also related to the average of suction. Since suction is related to unsaturated soil stiffness, these analyses were conducted to observe the effect of the global stiffness of the soil on the behavior of the structure. Results indicates that $\varepsilon_{\max }$ decreases with the global suction with a similar trend in which the FOS increases. Interestingly, the trends were found to be linear. These observations suggest the use of average of suction (global suction) as a representative of the infiltration effect in design analysis of unsaturated geotextile-reinforced soil walls subjected to infiltration.

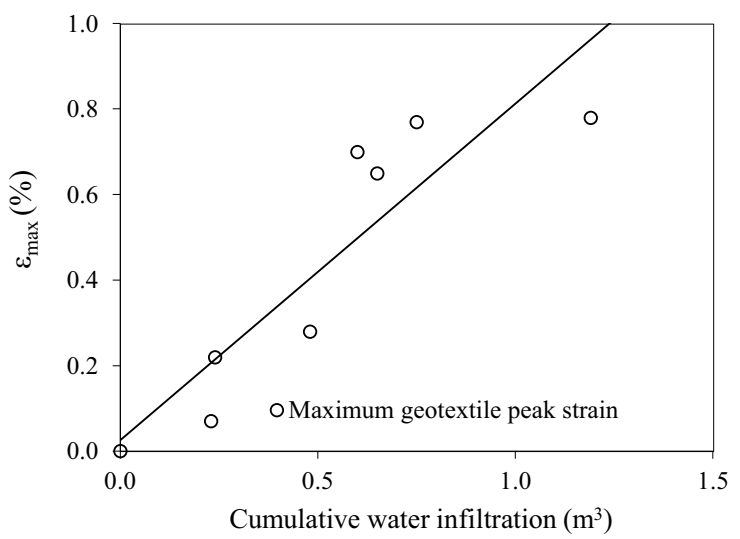

Fig 10. Effect of cumulative water infiltration on factor of safety and geotextile maximum peak strains $\left(\varepsilon_{\max }\right)$.

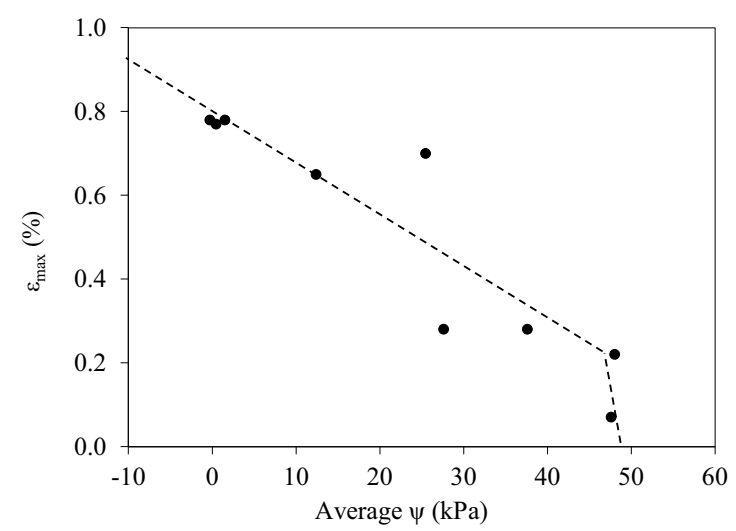

Fig 11. Effect of average suction increases on factor of safety and Geotextile maximum peak strains $\left(\varepsilon_{\max }\right)$.

\section{Conclusions}

The following conclusions can be drawn from analysis of the experimental results obtained in this study:

- Capillary breaks developed during infiltration, which retarded the infiltration in 4 days (per reinforced layer) until the breakthrough suction is achieved and geotextiles become more permeable than soil (suction value of $20 \mathrm{kPa}$ ). Nonwoven geotextiles did not provide internal drainage of the reinforced wall while the capillary effect is acting. However, after breakthrough, nonwoven geotextiles were found to improve the internal drainage in approximately $25 \%$.

- Infiltration showed a significant increasing on reinforcement strains. The moisture increase (capillary break) and subsequent breakthrough of the lower layers were observed to lead to increases in reinforcement strains. However, the moisture 
accumulation in top layers, which resulted in an increase in unit weight of the soil, is observed to result in increases in geotextile strains in the multiple lower layers.

- Increases in reinforcement strains of the geotextilereinforced soil wall were found to be more strongly related to the depth of moisture front than to increases in soil moisture values. This finding is related to the reduction of global stiffness of backfill soil, which is attributed to the progressive loss of overall backfill suction due to infiltration.

- As the global suction was found to better represent infiltration, designers should insight for the use of SWRC for analyses of these type of structures when considering unsaturated backfill soil.

\section{Acknowledgements}

The authors specially acknowledge the late Professor Benedito de Souza Bueno for his significant contribution to this study. The authors also wish to extend their appreciation to the CNPq and FAPESP funding.

\section{References}

1. J.G. Zornberg \& J.K. Mitchell. (1994). Reinforced soil structures with poorly draining backfills, Part I. Geosynthetics International, 1 (2), pp. 103-148. https://doi.org/10.1680/gein.1.0006

2. R. M. Koerner, and T. Y. Soong, (2001). Geosynthetic Reinforced Segmental Retaining Walls. Geotextextiles and. Geomembranes, Vol 19, No. 6, pp. 359-386. https://doi.org/10.1016/S0266-1144(01) 00012-7

3. C. Yoo, \& H. Y Jung. (2006). Case History of Geosynthetic Reinforced Segmental Retaining Wall Failure. J. Geotech. Geoenviron. Eng., Vol. 132, No. 12, pp. 1538-1548. https:// doi.org/10.1061/(ASCE)10900241(2006)132:12(1538)

4. F.H.M. Portelinha \& J. G. Zornberg (2017). Effect of Infiltration on the Performance of an Unsaturated Geotextile-Reinforced Soil Wall. Geotextiles and Geomembranes, Vol. 45, No. 3, pp. 211-226. https://doi.org/10.1016/j.geotexmem.2017.02.002

5. P. A. S. Carvalho, J. A. B. A. Pedrosa, C. M. Wolle. (1986). Geotextile reinforced embankment - an alternative to geotechnical engineering. Proceedings of Brazilian Conference on Soil Mechanics and Foundations, 8, Porto Alegre, RS, Brazil, October 1986, pp. 169- 178 (in Portuguese).

6. J. K. Mitchell, J. G. Zornberg. (1995). Reinforced Soil Structures with Poorly Draining Backfills, Part II: Case Histories and Applications. Geosynthetics International, 2 (1), pp. 265-307. https://doi.org/10.1680/gein.2.0011

7. F. H. M. Portelinha, B. S. Bueno, J. G. Zornberg. (2013). Performance of nonwoven geotextile reinforced soil walls under wetting conditions : laboratory and field investigation. Geosynthetics International, 20 (2), pp. 90-104. https://doi.org/10.1680/gein.13.00004

8. F. H. M. Portelinha, J. G.Zornberg, V. Pimentel. (2014). Field Performance of retaining walls reinforced with woven and nonwoven geotextiles. Geosynthetics

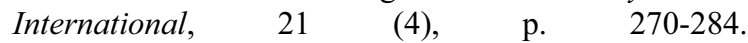
https://doi.org/10.1680/gein.14.00014

9. J. G. Zornberg, A. Bouazza, J. S. McCartney. (2010). Geosynthetic capillary barriers: current state of knowledge. Geosynthetics International, v. 17, n. 5, p. 273-300. https://doi.org/10.1680/gein.2010.17.5.273

10. M. Khire, C. Benson, P. Bosscher. (2000). Capillary barriers in semiarid and arid climates: design variables and the water balance. Journal of Geotechnical and Geoenvironmental Engineering, ASCE, 126, No. 8, 695-708.https://doi.org/10.1061/(ASCE)10900241(2000)126:8(695)

11. D.G. Fredlund, N.R. Morgernstern (1977). Stress state variables for unsaturated soils. ASCE J. Geotech. Engng Div. 103 (No. GT5), pp. 447-466. https://doi.org/10.1061/AJGEB6.0000423

12. D. G. Fredlund, N. R. Morgentern, R. A. Widger. (1978). The shear strength of unsaturated soils. Canadian Geotechnical Journal, V. 15, No. 3, pp. 313321. https://doi.org/10.1139/t78-029

13. S.K. Vanapalli, D.G. Fredlund, M.D. Pufahl, A.W. Clifton. (1996). Model for prediction of shear strength with respect to soil suction. Can. Geotechnical J. 33 (3), pp. 379-392. https://doi.org/10.1139/t96-060

14. N. Khalali, M.H. Khabbaz, (1998). A unique relationship for shear strength determination of unsaturated soils. Geotechnique 48 (No. 5), p. 681-688. https://doi.org/10.1680/geot.1998.48.5.681

15. E.A.M. Marinho, R.J. Chandle, M.S. Crilly (1995). Stiffness measurements on an unsaturated high plasticity clay using bender elements. In: Proc. 1st Int. Conf. On Unsaturated Soils, vol. 2, pp. 535-539. Paris.

16. C. Mancuso, R. Vassallo, A. d'Onofrio (2002). Small strain behavior of a silty sand in controlled-suction resonant column e torsional shear tests. Can. Geotech. J. 39 (No. 1), pp. 22-31. https://doi.org/10.1139/t01-076

17. C.W.W. Ng, S.Y. Yung. (2008). Determination of the anisotropic shear stifness of an unsaturated decomposed soil. Geotechnique 58, pp. 23-35. https://doi.org/10.1680/geot.2008.58.1.23

18. C.W.W. Ng, J. Xu, (2012). Effects of current suction ratio and recent suction history on small-strain behaviour of an unsaturated soil. Can. Geotechnical J. 49, pp. 226-243. https://doi.org/10.1139/t11-097

19. G. B. Georgetti, O.M. Vilar, R. A. Rodrigues, (2013). Small-strain shear modulus and shear strength of an unsaturated clayey sand. In: 18th International Conference on Soil Mechanics and Geotechnical Engineering, 2013, Paris. Proceedings.... Paris : Presses des Ponts, 2013. v. 1. p. 1113-1116.

20. M.Th. van Genuchten (1980). A closed-form equation for predicting the hydraulic conductivity of unsaturated soils. Soil Sci. Soc. Am. J., 44, pp. 892-898. https://doi.org/10.2136/sssaj1980.03615995004400050 $002 x$

21. Y. Mualem, (1976). A new model for predicting the hydraulic conductivity of unsaturated porous media. Water Resour. Res., 12, pp. 513-522. https://doi.org/10.1029/WR012i003p00513 